\title{
Correction to: Juvenile idiopathic arthritis in Harlequin ichthyosis, a rare combination or the clinical spectrum of the disease? Report of a child treated with etanercept and review of the literature
}

Francesco Baldo ${ }^{1,2}$, Michela Brena ${ }^{3}$, Simone Carbogno ${ }^{1,2}$, Francesca Minoia', Stefano Lanni', Sophie Guez ${ }^{1}$ Antonella Petaccia ${ }^{1}$, Carlo Agostoni ${ }^{1,2}$, Rolando Cimaz $^{4,5}$ and Giovanni Filocamo ${ }^{1 *}$

Correction to: Pediatr Rheumatol 19, 80 (2021)

https://doi.org/10.1186/s12969-021-00571-9

Following publication of the original article [1], the authors identified an error in the author name of Stefano Lanni.

- The incorrect author name is: Stefani Lanni

- The correct author name is: Stefano Lanni

The author group has been updated above and the original article [1] has been corrected.

\footnotetext{
Author details

'Pediatric Rheumatology, Fondazione IRCCS Ca' Granda Ospedale Maggiore Policlinico, Milan, Italy. ${ }^{2}$ University of Milan, Milan, Italy. ${ }^{3}$ Dermatology Unit, Fondazione IRCCS Ca' Granda Ospedale Maggiore Policlinico, Milan, Italy. ${ }^{4}$ ASST G.Pini-CTO, Milan, Italy. ${ }^{5}$ Department of Clinical Sciences and Community Health, and RECAP-RD, University of Milan, Milan, Italy.
}

Published online: 23 July 2021

\section{Reference \\ 1. Baldo F, Brena M, Carbogno S, et al. Juvenile idiopathic arthritis in Harlequin ichthyosis, a rare combination or the clinical spectrum of the disease? Report of a child treated with etanercept and review of the literature. Pediatr Rheumatol. 2021;19:80. https://doi.org/10.1186/s12969-021-00571-9.}

The original article can be found online at https://doi.org/10.1186/s12969021-00571-9.

* Correspondence: giovanni.filocamo@policlinico.mi.it

'Pediatric Rheumatology, Fondazione IRCCS Ca' Granda Ospedale Maggiore Policlinico, Milan, Italy

Full list of author information is available at the end of the article

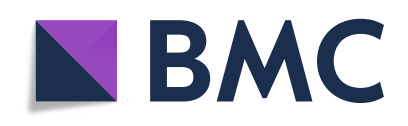

(c) The Author(s). 2021 Open Access This article is licensed under a Creative Commons Attribution 4.0 International License, which permits use, sharing, adaptation, distribution and reproduction in any medium or format, as long as you give appropriate credit to the original author(s) and the source, provide a link to the Creative Commons licence, and indicate if changes were made. The images or other third party material in this article are included in the article's Creative Commons licence, unless indicated otherwise in a credit line to the material. If material is not included in the article's Creative Commons licence and your intended use is not permitted by statutory regulation or exceeds the permitted use, you will need to obtain permission directly from the copyright holder. To view a copy of this licence, visit http://creativecommons.org/licenses/by/4.0/ The Creative Commons Public Domain Dedication waiver (http://creativecommons.org/publicdomain/zero/1.0/) applies to the data made available in this article, unless otherwise stated in a credit line to the data. 